\title{
DRACUNCULIASIS ERADICATION: THE FINAL INCH
}

\author{
DONALD R. HOPKINS, * ERNESTO RUIZ-TIBEN, PHILIP DOWNS, P. CRAIG WITHERS, JR., AND JAMES H. MAGUIRE \\ The Carter Center, Atlanta, Georgia; Division of Parasitic Diseases, National Center for Infectious Diseases, Centers for Disease \\ Control and Prevention, Atlanta, Georgia
}

\begin{abstract}
This report summarizes the status of the Dracunculiasis Eradication Program as of early 2005. Nine of the 20 countries that were endemic for this disease when the program began have already interrupted transmission, Asia is free of Guinea worm, and five of the remaining disease-endemic countries reported less than 50 cases each in 2004. Ghana and Sudan each reported $45 \%$ of the 16,026 cases in 2004. Except for Sudan, whose reports are delayed, cases in the remaining disease-endemic countries were reduced by $61 \%$ during the first quarter of 2005 compared with the same period of 2004. With accelerating momentum towards zero cases in all countries, the recent settlement of Sudan's north-south civil war, and a new challenge grant from the Bill \& Melinda Gates Foundation, the way now seems clear to finish eradicating dracunculiasis by 2009 in Sudan and earlier elsewhere.

"The rule of the final inch ... The work has been almost completed, the goal almost attained ... In that moment of fatigue and self-satisfaction it is especially tempting to leave the work without having attained the apex of quality ... In fact, the rule of the Final Inch consists in this: not to shirk this crucial work. Not to postpone it ... And not to mind the time spent on it, knowing that one's purpose lies ... in the attainment of perfection."

-Alexander Solzhenitzyn, The First Circle
\end{abstract}

\section{INTRODUCTION}

The global Dracunculiasis Eradication Program (DEP) has accelerated its momentum towards the goal of total eradication since the previous review of the program was published three years ago. ${ }^{1}$ This paper summarizes the status of the program as of early 2005.

In previous reports, we have described the parasite Dracunculus medinensis, its transmission, prevention, and the strategies and progress of earlier stages of the eradication program. ${ }^{1,2}$ The infection (dracunculiasis or guinea worm disease) is transmitted to humans in contaminated drinking water containing copepods (water fleas) that are infected with larvae of the parasite. The larvae are expelled into water by adult worms that emerge through the skin of infected people approximately one year after the people become infected. Emergence of the adult worms is slow, painful, and disabling (though usually not fatal), and therein lies its serious adverse socioeconomic impact on the health, agricultural production, and school attendance of affected populations. Individuals are incapacitated for periods averaging 2-3 months, and more than half of a village's population may be affected at the same time during the main harvest or planting season. Humans are the only reservoir of infection. Individual infections last only one year, but people do not develop immunity to the parasite. There is no effective treatment or vaccine, but the infection may be prevented by educating villagers about the origin of the disease and about the need to prevent infected persons from entering sources of drinking water, and to always filter their drinking water through a finely woven cloth that removes the copepods; by using Abate ${ }^{\circledR}$ larvicide (temephos; BASF Corporation, Mount Olive, NJ) to kill the copepods and larvae in the open ponds and other stagnant sources of drinking water; and by providing clean drinking water from safe sources such as protected hand dug wells or borehole wells.

* Address correspondence to Donald R. Hopkins, The Carter Center, 453 Freedom Parkway, Atlanta, GA 30307. E-mail: sdsulli@emory .edu
This global eradication campaign began at the Centers for Disease Control and Prevention (CDC) in 1980, and was adopted as a sub-goal of the International Drinking Water Supply and Sanitation Decade (1981-1990). Since 1986, the campaign has been led by The Carter Center, in close cooperation with CDC, the United Nations Children's Fund (UNICEF), and the World Health Organization (WHO). It is implemented by thousands of village volunteers and supervisory health staff in disease-endemic countries, and supported by dozens of donor agencies, governments, foundations, and other institutions.

\section{CURRENT STATUS OF THE CAMPAIGN}

By the end of 2004, 9 of the 20 countries that were endemic for dracunculiasis when the campaign began had interrupted transmission of this disease (including all three affected Asian countries), the number of infected persons had been reduced by more than $99 \%$ from an estimated 3.5 million persons in $1986^{3}$ to 16,026 cases in 2004 , the number of disease-endemic villages had been reduced from more than 23,000 in 1993 to 3,109 in 2004, and the WHO had officially certified 168 of the world's 192 countries as free of dracunculiasis. Uganda, which reported more than 126,000 cases of dracunculiasis during its national case search in 1991, reported zero cases for the first time during an entire calendar year in 2004. Nigeria, which reported more than 653,000 cases during its national case search in 1988-1989, reported less than 500 cases, and three other countries (Benin, Ethiopia, and Mauritania) reported only three indigenous cases each (Figure 1 and Table 1).

Ghana and Sudan each reported 45\% of all cases in 2004 . Ghana's program appears to have finally ended a decade of disappointing stagnation that followed disruptive ethnic fighting in its most disease-endemic area in 1994, achieving a $44 \%$ reduction in cases during the last half of 2004 compared with the same period a year earlier, and a reduction of $59 \%$ during the first three months of 2005 compared with the same three months of 2004. Beginning in 2002, more than 6,500 members of Ghana Red Cross Society Mothers Clubs were mobilized to help conduct surveillance for cases and health education in 
Distribution by Country of 129,834 Cases of Dracunculiasis Reported during 1995

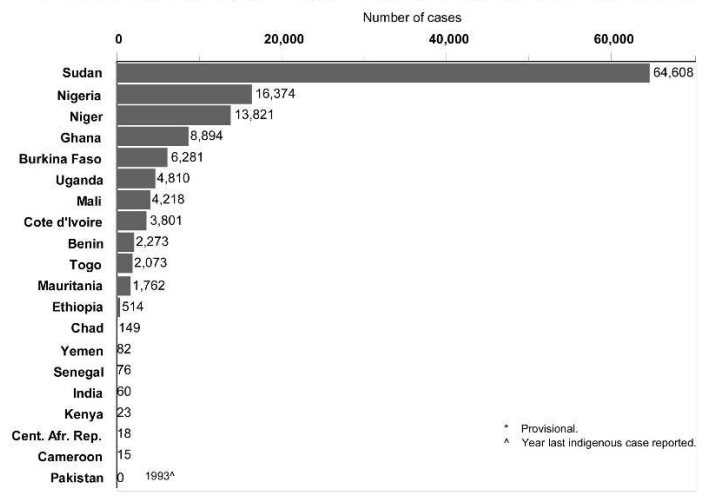

Distribution by Country of 63,606 Indigenous Cases of Dracunculiasis Reported during 2001

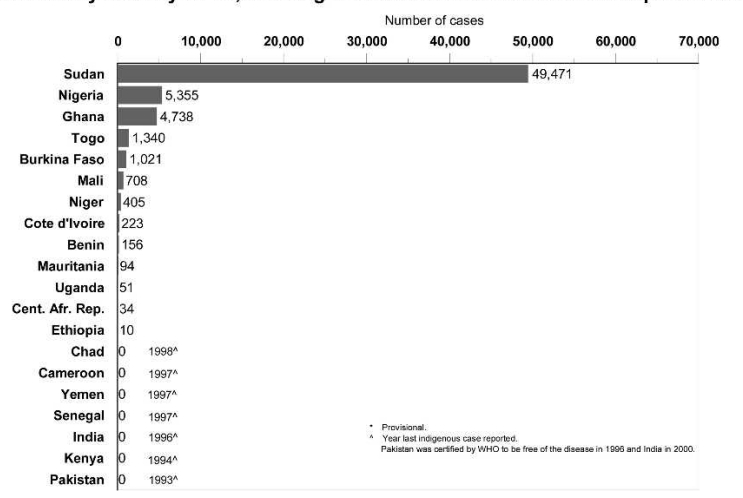

Distribution by Country of 78,293 Indigenous Cases of Dracunculiasis Reported during 1998

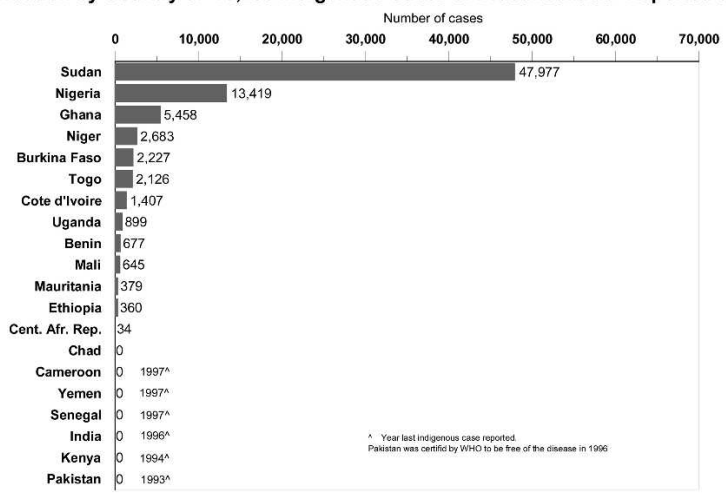

Distribution by Country of 15,912 Indigenous Cases of Dracunculiasis Reported during 2004

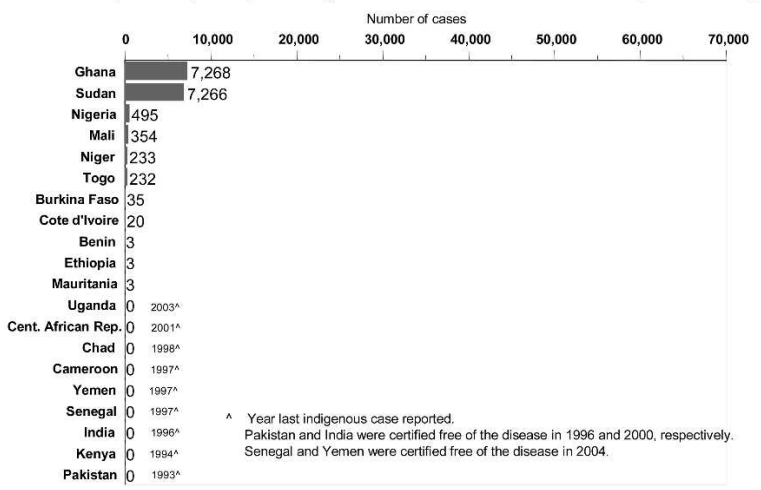

FIGURE 1. Distribution of dracunculiasis cases by country for 1995, 1998, 2001, and 2004. WHO = World Health Organization.

disease-endemic villages, thus supplementing the manpower of existing village volunteers. Since 2003, the Government of Ghana has allocated more than US $\$ 3$ million for improved water supplies in disease-endemic villages, as well as more funding for other aspects of its program.

Sudan, which has long been the main obstacle to completing the global campaign, ${ }^{4}$ reduced its reported cases by $51 \%$ between 2002 and 2003 (from 41,493 cases to 20,299), and by $67 \%$ (to 7,266 cases) between 2003 and 2004, despite the civil war. It followed up that epidemiologic achievement with the important political news of a signed Comprehensive Peace Agreement to formally end the 21-year-old civil war early in 2005 , thus opening the way to access the remaining diseaseendemic areas of Sudan. Sudan ended indigenous transmission of dracunculiasis in its northern states in 2002, so all remaining disease-endemic areas are in the war-torn south. The Sudan Guinea Worm Eradication Program distributed more than seven million pipe filters for personal protection of inhabitants traveling or displaced from home in 2001, held more than 100,000 health education sessions annually in 2002 , 2003, and 2004, and distributed a cumulative total of more than 3.5 million household cloth filters in 2001-2004, covering approximately $89 \%$ of all households in accessible villages. The extraordinary effort in which The Carter Center joined an initiative of Health and Development International, and Norwegian industry and government, to manufacture and distribute more than nine million pipe filters in Sudan in 20012002, was followed by another exceptional effort in which Norwegian medical students raised more than $\$ 200,000$ in their Humanitarian Action Campaign in 2003 for providing enough first aid kits for containment of dracunculiasis cases throughout Sudan for more than a year.

The main problem area remaining in west Africa outside of Ghana comprises seven districts in the contiguous tri-border area of Burkina Faso (Djibo, Gorom Gorom), Mali (Ansongo, Gourma Rharous, Gao), and Niger (Tera, Tillaberi), where nomadic Black Tuaregs are the group at highest risk. The affected areas of Mali and Niger contain most of the remaining cases in this area (328 and 179, respectively, of 530 total cases reported from the tri-border area in 2004). Insecurity delayed access by Mali and Niger's programs to this area for two or three years. In 2003 and 2004, Mali improved supervision of village volunteers, increased distribution of cloth and pipe filters, and conducted its first "Worm Weeks" of intensive health education and mobilization of inhabitants in the highest disease-endemic zones. A special initiative to provide safe water sources to several high-priority, diseaseendemic villages in the relevant areas of Mali and Niger (also Togo) is being implemented in 2005. After a dramatic public speech in which he declared his "profound disappointment" with the progress of his country's Guinea Worm Eradication Program, the president of Mali replaced that program's national manager in February 2005.

Nigeria, which with Sudan and Ghana was a long-time member of the "big three" disease-endemic countries, continued to ratchet up its interventions as it reduced cases and expanded the guinea worm-free areas of the country. Between 2001 and 2004, for example, the proportion of diseaseendemic Nigerian villages that had at least one source of safe drinking water increased from $51 \%$ to $71 \%$, the proportion of 


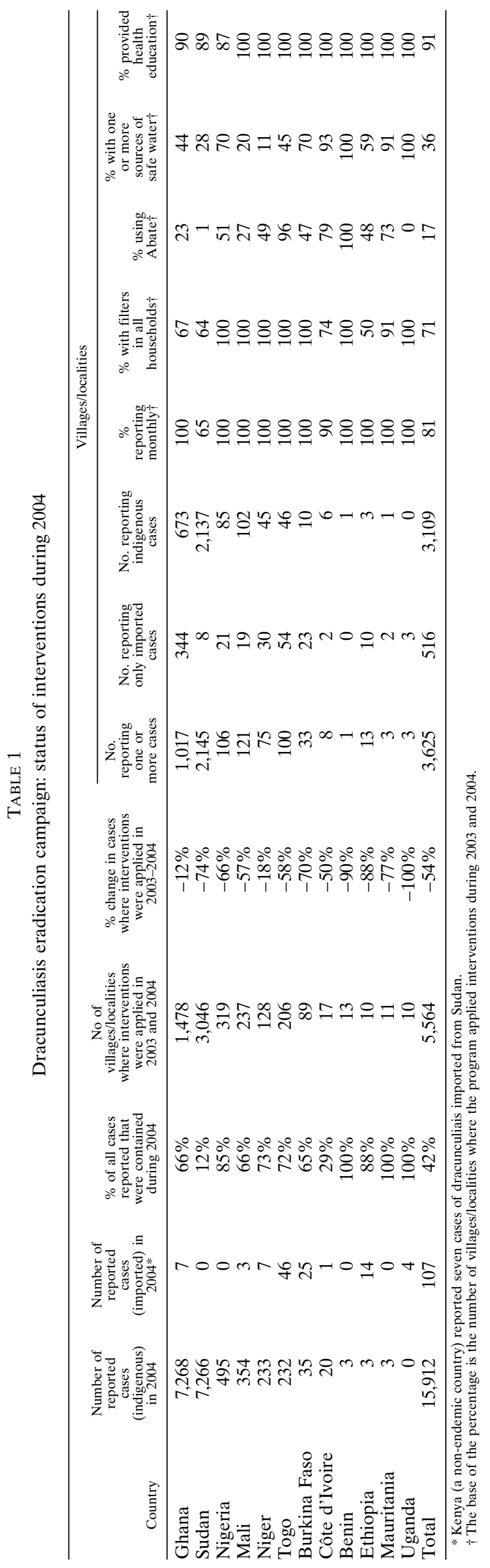

disease-endemic villages with cloth filters in all households increased from $89 \%$ to $100 \%$, and the percentage of each year's cases that were contained increased from $65 \%$ to $85 \%$. Only 85 Nigerian villages were endemic for dracunculiasis in 2004 , in 35 of the country's 774 local government areas, and only 7 of the 36 states.

After a $10 \%$ increase (from 1,344 to 1,479 ) in indigenous cases between 2001 and 2002, Togo's program reduced its indigenous cases by $58 \%$ in 2003 (to 622 ) and by another $63 \%$ in 2004 (to 232). Togo has also had to deal with cases of dracunculiasis imported from neighboring Ghana over the same four years: 10, 23, 47, and 46 cases, respectively. Togo began using regional "Case Containment Centers", where dracunculiasis patients could be isolated voluntarily and receive primary health care for the illness, as an innovative intervention in disease-endemic southern areas of the country in August 2001. By January-September 2004, the percentage reduction in cases in six districts with such centers was $75 \%$, versus a $52 \%$ reduction in cases in twelve districts without such centers, compared with the same period of 2003. In northern Togo, where most of the unpredictable cases imported from Ghana occur, the program uses local technical assistants to help take care of patients and implement intensive case containment in the patients' own villages and compounds. By late 2004, all disease-endemic districts were achieving comparably high reductions in cases.

By the end of March 2005, Benin had attained 12 consecutive months without an indigenous case of dracunculiasis, whereas Ethiopia and Mauritania had not had an indigenous case in nine months. A total of 114 cases were exported internationally in 2004, including 57 from Ghana, 25 from Sudan, and 17 from Mali. The intensification of technical assistance provided to disease-endemic countries, U.S. Peace Corps-inspired "Worm Weeks" of health education and mobilization in the highest disease-endemic villages, and expansion of case containment centers (CCCs) are shown in Figure 2. Patients who are cared for in the CCCs are incapacitated for much shorter periods, on average, than those who are not (18 days versus 51 days in Ghana and Togo) (Hochberg N, unpublished data), and CCCs thus serve to engage primary health care services to benefit dracunculiasis patients and the Dracunculiasis Eradication Program.

Over the past two years especially, The Carter Center has spearheaded an intensified media campaign and worked with WHO and UNICEF to help mobilize political and medical leaders of all remaining disease-endemic countries. The mass media campaign is built around the theme, "Stop Guinea Worm Now: Prevent It! Avoid It! Report It!" It has included recorded public service announcements and interviews by United Nations Secretary General Kofi Annan, President Carter, President Amadou Toumani Toure of Mali, President Mamadou Tandja of Niger, Nigerian former head of state General (Dr.) Yakubu Gowon, and others, which have been broadcast on radio and/or television by the Voice of America, British Broadcasting Corporation, and Cable News Network International, as well as by national and local radio and television stations in disease-endemic countries (Figure 3). The prominent citation of President Carter's work to eradicate dracunculiasis among his achievements recognized by the Nobel Peace Prize committee in October 2002 was an unplanned addition in this campaign. Other important components of these efforts included a special program review for the Dra- 

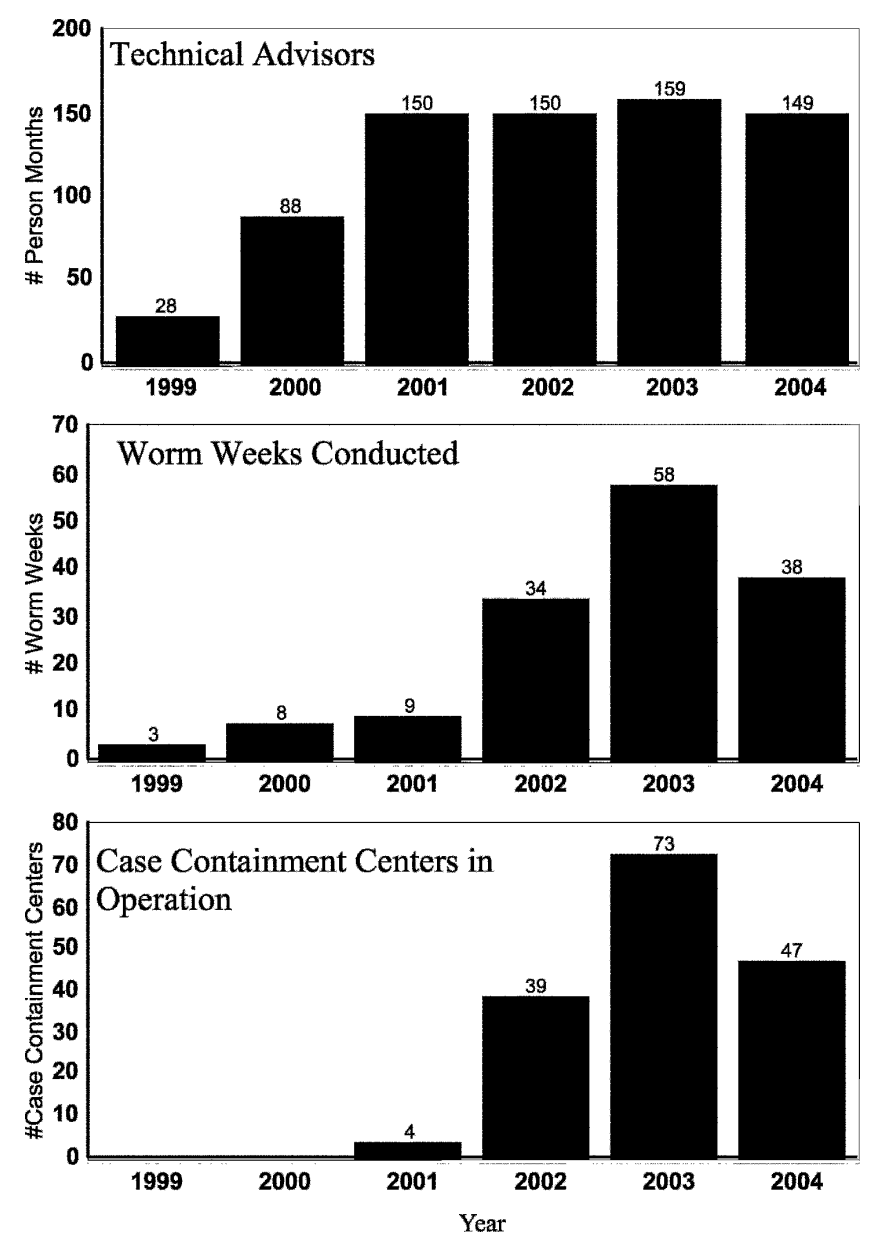

FIGURE 2. Number of person months of technical assistance provided, number of worm weeks conducted, and number of case containment centers in operation during 1999-2004.

cunculiasis Eradication Programs of Sudan, Ghana, and Nigeria that was hosted by The Carter Center in Atlanta in September 2003 and attended by Dr. Jong-Wook Lee, the director general of WHO, General Gowon of Nigeria, and Kul Gautam, the deputy executive director of UNICEF, as well as by President Carter and ministerial level representatives from Ghana, the Government of Sudan, and the Sudan People's Liberation Movement. President Carter, Dr. Lee of WHO, and Mr. Gautam of UNICEF made a joint visit to Ghana in February 2004, visited disease- endemic villages, and met with the President of Ghana to discuss Ghana's Dracunculiasis Eradication Program. In May 2004, President Carter visited the World Health Assembly and met with the ministers of health or their representatives from all of the remaining disease-endemic countries, in the presence of highranking officials from WHO and UNICEF, and the chairman of the International Commission for the Certification of Dracunculiasis Eradication. The ministers signed a "Geneva Declaration" in which they pledged to finish eradicating dracunculiasis by 2009 (for Sudan) or before (for all other diseaseendemic countries). ${ }^{5}$ The entire World Health Assembly then adopted a formal resolution (WHA 57.9) that endorsed the same goal and target date. Meanwhile, in 2004, the prime minister of Togo and the ministers of health of Benin, Burkina Faso, Niger, and Togo visited disease-endemic villages in their respective countries.

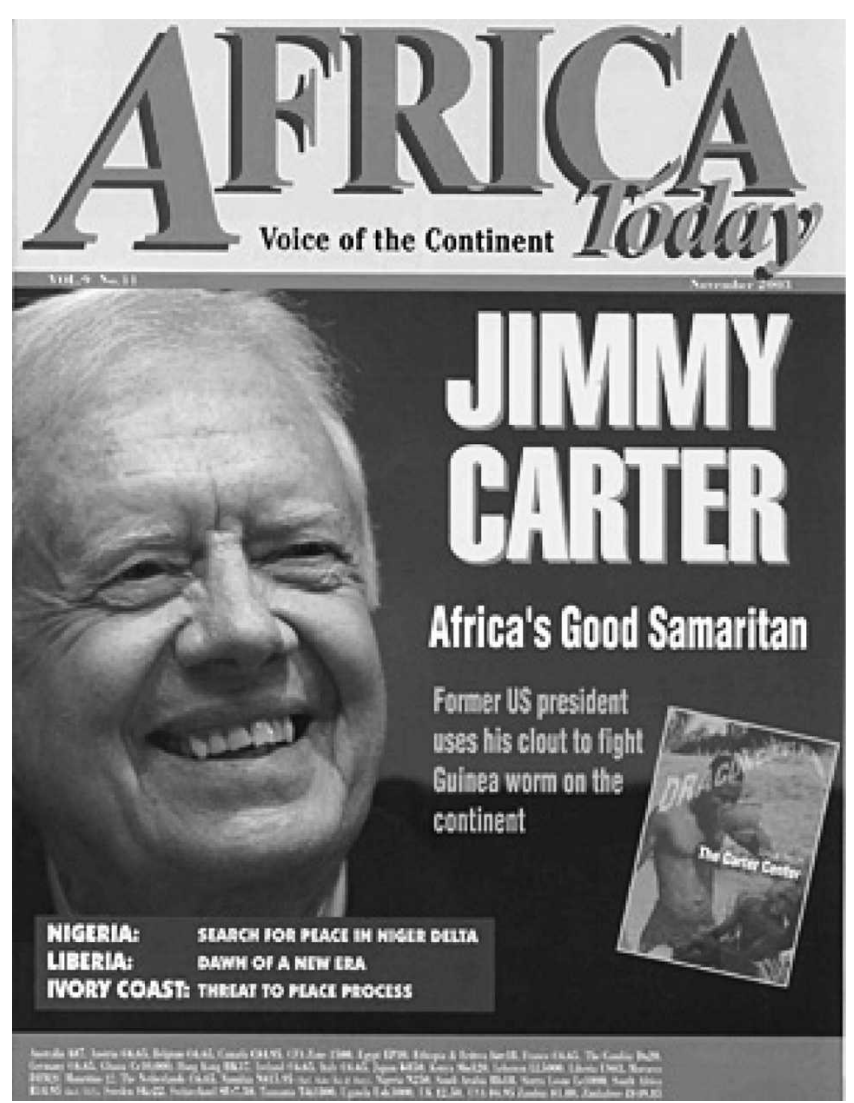

FIGURE 3. Frontispiece of the article on Jimmy Carter and guinea worm disease. (Reprinted with permission of Africa Today, November 2003, Volume 9(11): 4-5, 17-37.)

The Carter Center provided some assistance to the Division of Parasitic Diseases at CDC in its recently successful effort to develop a DNA probe to reliably distinguish between $D$. medinensis of humans and $D$. insignis species, which affect other animals. A recent report describes this new tool, which is badly needed in the final stages of the eradication campaign. ${ }^{6}$

\section{DISCUSSION}

The accelerating reduction in cases of dracunculiasis in virtually all of the remaining disease-endemic areas over the past three years is a welcome and timely development since momentum towards dracunculiasis eradication resumed in $2000^{7}$ (Figures 4-6). The recent and long-awaited political agreement to bring peace to southern Sudan removes at last the single most important obstacle to completing this eradication campaign. We still believe that 4-5 years of peace will be required before Sudan reaches zero cases, but with the invaluable head start and experience Sudan's Guinea Worm Eradication Program gained since the four-month "Guinea Worm Cease-Fire" that President Carter negotiated in 1995, Sudan is now well on its way. A new challenge in post-war southern Sudan will be to ensure that this eradication effort, and that for polio, are given priority by all concerned because of their necessarily singular natures as eradication programs. Although it is only one of many diseases, and usually is not fatal, eradicating dracunculiasis can be a powerful, broad- 


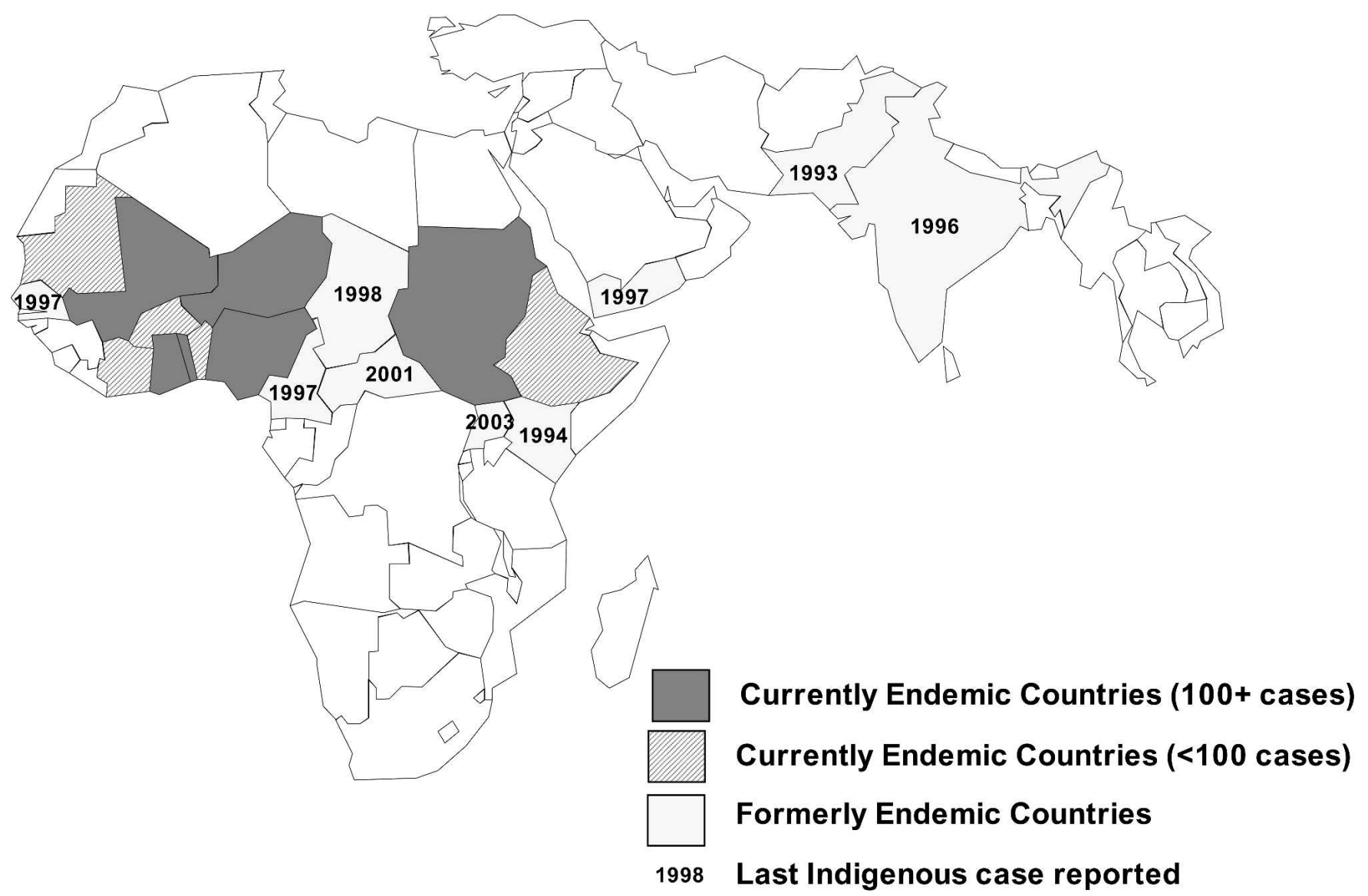

FIGURE 4. Dracunculiasis Eradication Program: status of eradication efforts in 2004.

based "engine for development" in post-war southern Sudan, by improving agricultural production and school attendance; developing village-based surveillance; building local capacity by screening and training village-based health workers; fostering the organization and functioning of village-based development committees; providing on-the-job managerial, planning, supervisory, and monitoring experience; promoting extension of clean drinking water sources to the most deprived villages; and providing a tangible, highly visible "Peace Dividend", in addition to eliminating dracunculiasis from its most important remaining stronghold.

Analysis of Sudan's impressive reduction in cases of dracunculiasis over the past two years shows that the dramatic decrease is the net result of several factors, although overall reporting rates are comparable for 2002, 2003, and 2004 (72$77 \%$ of disease-endemic villages reporting). They include a complex mixture of over-reporting, under-reporting, formerly reporting areas becoming inaccessible, new reporting from areas being accessed for the first time (especially after the cease-fire that began in October 2002 as part of the ultimately successful political negotiations), as well as decidedly effective interventions by the program during those years, as outlined earlier. It is impossible to ascertain the precise contributions of each of these factors to the net result, but any doubt that the recent reductions in Sudan's cases are real and substantial is dispelled by the observation that the number of villages reporting zero cases of dracunculiasis among a cohort of 3,279 disease-endemic villages reporting from January 2001 through August 2004 has steadily increased from 1,443 in 2001 to 2,957 during January-August 2004, whereas the number of disease-endemic villages reporting 1-4 cases and villages reporting $\geq 5$ cases has decreased annually since 2001 . The number of villages reporting $\geq 5$ cases in this cohort decreased from 1,288 in 2001 to 173 during January-August 2004, a reduction of $87 \%$. Moreover, the number of cases exported from southern Sudan to northern Sudanese states and neighboring countries also decreased by a remarkable $51 \%$, from 69 to 34, between 2003 and 2004.

The importance of mobilizing political leaders and strong political will has been illustrated repeatedly throughout this campaign. As described in the previous review, ${ }^{1}$ involvement of former Nigerian head of state General Yakubu Gowon, and former head of state, now President Amadou Toumani Toure of Mali, with their sustained, passionate advocacy throughout Nigeria and the francophone disease-endemic countries, are major factors in the recent successes of those programs. In Uganda, which is another former member of the highest disease-endemic country club, the Dracunculiasis Eradication Program also benefited from consistent support by the country's political and public health leaders. As also mentioned in the previous review, these advantages were greatly complemented by the generous funding provided by a grant from the Bill \& Melinda Gates Foundation in 2000, and both the political and financial advantages have come to fuller realization during the most recent three years of the program that are the subject of this review. Continuity of financial 

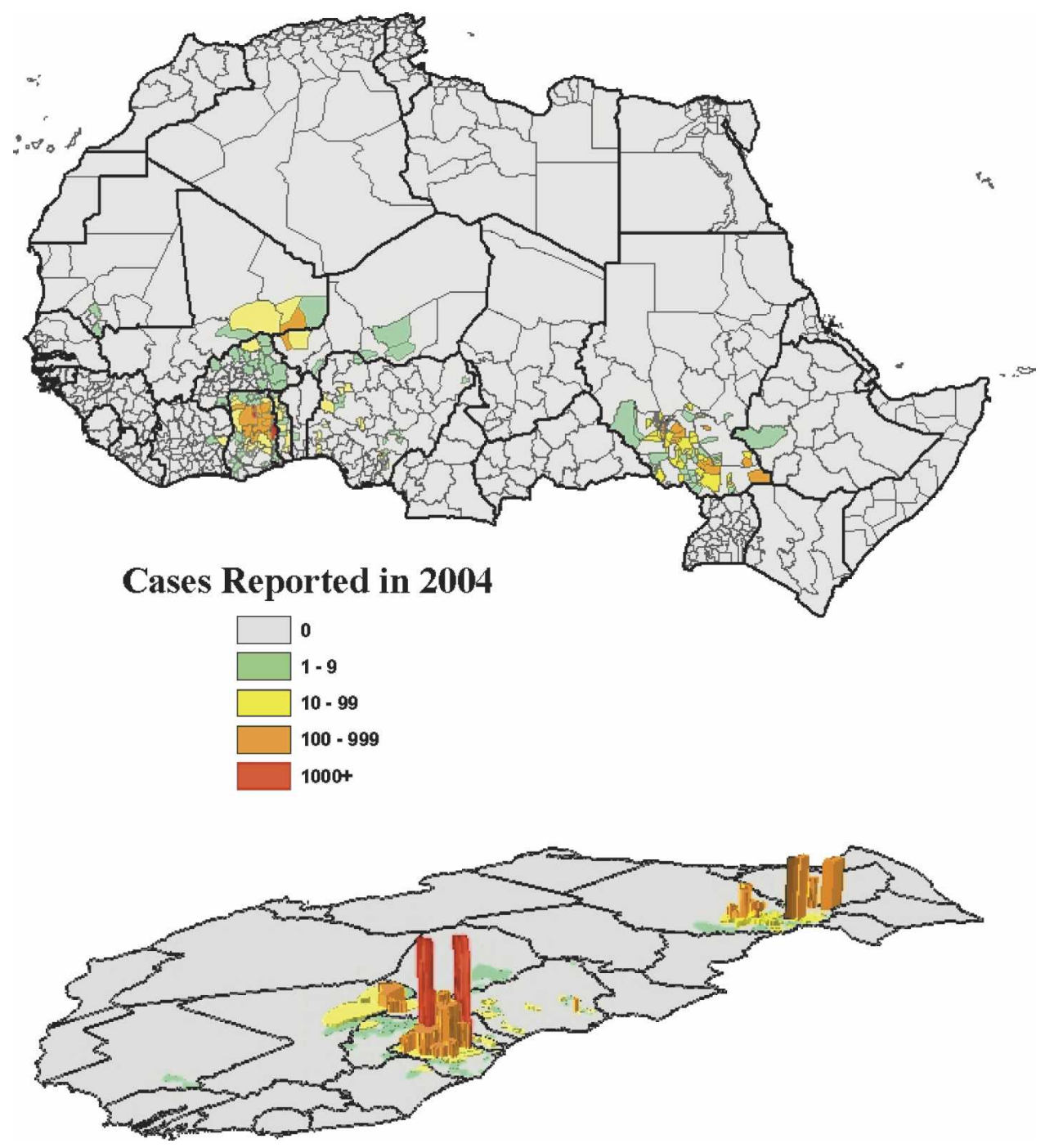

Figure 5. Distribution of 16, 026 cases of dracunculiasis by district in Africa, 2004.

support was assured by another generous challenge grant from the Bill \& Melinda Gates Foundation in March 2005.

Insecurity continues to hinder operations in some important areas such as Akobo District in Ethiopia, and Côte d'Ivoire, for example, even though the main impediment of Sudan's civil war is now over (significant insecurity still remains in parts of southern Sudan). Complacency and apathy are still important concerns in some quarters and among some health personnel, but this is most often manifest now by lack of urgency in responding to suspected cases of dracunculiasis, and by inadequacy of surveillance for dracunculiasis in formerly disease-endemic areas or areas not disease endemic in most African countries concerned, including many that have reduced or apparently eliminated the disease at great cost. One final factor that has become more evident in recent years is the existence of neglected marginalized populations such as the Black Tuaregs of Mali and Niger, and the Konkomba ethnic group in Ghana and Togo, who dominate some of the pockets of disease remaining, but who were previously overlooked and/or their significance unrecognized, by the respective Dracunculiasis Eradication Programs.

With the increasing momentum summarized above, the
Peace Agreement in Sudan, and the new challenge grant from the Bill \& Melinda Gates Foundation, the way now seems clear to meet the revised target date for completing the eradication of dracunculiasis. And not a year too soon. We are now in the realm of The Final Inch.

Received May 5, 2005. Accepted for publication May 13, 2005.

Acknowledgments: We gratefully acknowledge the assistance of Renn McClintic-Doyle and Shandal Sullivan in preparing this manuscript. We also acknowledge the contributions of the national coordinators, village-based volunteers, other health workers in the disease-endemic countries, and other staff of The Carter Center and the WHO Collaborating Center for Research, Training, and Eradication of Dracunculiasis at CDC, without whose efforts these achievements would not have been possible. We publish this paper in memory of Dr. Robert L. Kaiser.

Financial support: In 2005, The Carter Center's work to eradicate guinea worm is made possible by financial and in-kind contributions from the Bill \& Melinda Gates Foundation, the Conrad N. Hilton Foundation, the Canadian International Development Agency, the AG Leventis Foundation, the United States Agency for International Development, CDC, the Organization of the Petroleum Exporting Countries Fund, the Salus Mundi Foundation, Vestergaard Frandsen, BASF Corporation, Mr. and Mrs. Michael D. Ranne, C. M. Gayle, 


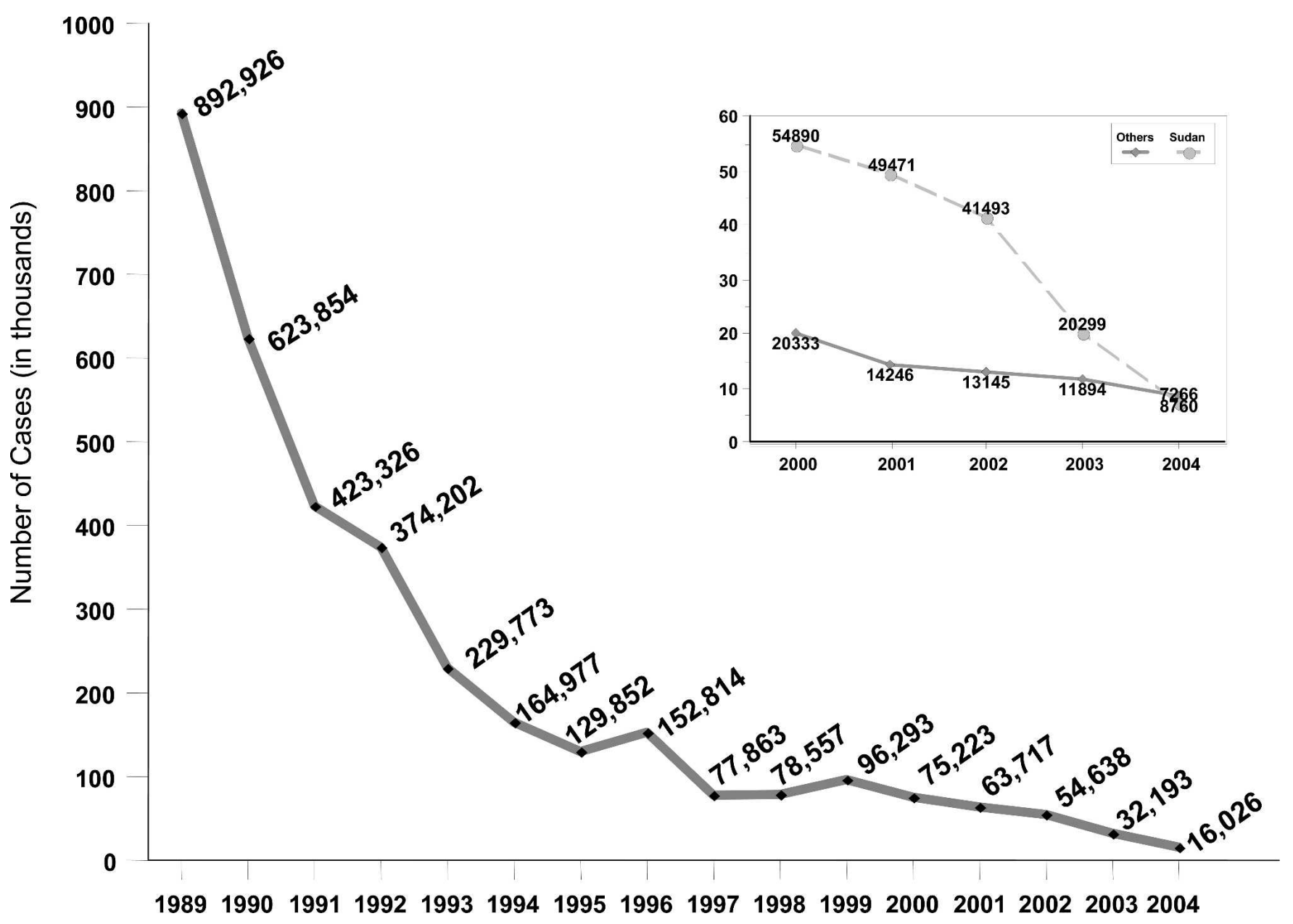

FiguRE 6. Number of reported cases of dracunculiasis by year, 1989-2004.

Jr., Dr. W. A. Baldwin, and the governments of Japan, Kuwait, Norway, Oman, and Saudi Arabia.

Authors' addresses: Donald R. Hopkins, The Carter Center, 453 Freedom Parkway, Atlanta, GA 30307, Telephone: 404-420-3837, Fax: 404-874-5515, E-mail: sdsulli@emory.edu. Ernesto Ruiz-Tiben, Guinea Worm Eradication Program, The Carter Center, 453 Freedom Parkway, Atlanta, GA 30307, Telephone: 770-488-4509, Fax: 770-488-4532, E-mail: exr1@cdc.gov. Philip Downs, Guinea Worm Eradication Program, The Carter Center, 453 Freedom Parkway, Atlanta, GA 30307, Telephone: 770-488-4507, Fax: 770-488-4532, Email: pid9@cdc.gov. P. Craig Withers, Jr., Program Support Health Programs, The Carter Center, 453 Freedom Parkway, Atlanta, GA 30307, Telephone: 404-420-3851, Fax: 404-874-5515, E-mail: cwither@emory.edu. James H. Maguire, University of Maryland School of Medicine, 660 West Redwood Street, Howard Hall, Suite 100, Room 102B, Baltimore, MD 21201, Telephone: 410-706-0206, Fax: 410-706-8013, E-mail: jmaguire@epi.umaryland.edu

Reprint requests: Donald R. Hopkins, The Carter Center, 453 Freedom Parkway, Atlanta, GA 30307.

\section{REFERENCES}

1. Hopkins DR, Ruiz-Tiben E, Diallo N, Withers PC Jr, Maguire JH, 2002. Dracunculiasis eradication: and now, Sudan. Am J Trop Med Hyg 67: 415-422.

2. Hopkins DR, Ruiz-Tiben E, 1991. Strategies for eradication of dracunculiasis. Bull World Health Organ 69: 533-540.

3. Watts SJ, 1987. Dracunculiasis in Africa in 1986: its geographic extent, incidence, and at-risk population. Am J Trop Med Hyg 37: 119-125.

4. Hopkins DR, Withers PC Jr, 2002. Sudan's war and eradication of dracunculiasis. The Lancet 360 (Suppl): s20-s22.

5. World Health Organization, 2004. Dracunculiasis eradication: Geneva declaration on guinea-worm eradication, Geneva, 2004. Wkly Epidemiol Rec 79: 234-235.

6. Bimi L, Freeman AR, Eberhard ML, Ruiz-Tiben E, Pieniazek NJ, 2005. Differentiation of Dracunculus medinensis and Dracunculus insignis by sequence analysis of the $18 \mathrm{~S}$ RNA. Ann Trop Med Parasitol 99: 1-7.

7. World Health Organization, 2005. Dracunculiasis eradication: global surveillance summary, 2004. Wkly Epidemiol Rec 80: 165-176. 